\title{
Artigos
}

Mariana Veríssimo Silva'

Angela Maria Scalabrin Coutinho2

\section{A política de priorização de vagas na creche no município de Curitiba}

Resumo: Este artigo é resultado de pesquisa realizada através do Programa Institucional de Bolsas de Iniciação Científica (PIBIC) no curso de Pedagogia da Universidade Federal do Paraná (UFPR), no decorrer do ano de 2016. A pesquisa realizada investigou se o direito à educação infantil das crianças de 0 a 3 anos está sendo efetivado na rede pública do município de Curitiba. Com o intuito de averiguar como ocorre a política de priorização de vagas, foi realizado um estudo de campo em um Centro Municipal de Educação Infantil (CMEI), com o acompanhamento das reuniões do conselho, nas quais foi discutida a priorização das vagas, além de análise documental do regimento, estatuto e atas do conselho escolar. Uma primeira conclusão é a de que o município não atende toda a demanda por vagas para crianças de 0 a 3 anos. Para 0 preenchimento das poucas vagas existentes, 0 conselho do CMEI, por meio dos critérios de priorização, seleciona algumas crianças seguindo orientações do regimento e do ofício circular enviado pela Secretaria Municipal de Educação no início do ano letivo.

Palavras-chave: Creche; Direito à Educação; Priorização de Vagas; Desigualdade social.

\section{The policy of prioritization of vacancies in nursery in the county of Curitiba}

Abstract: This article is the result of the research realized through the Institutional Scholarship Program of Scientific iniciation in the course of Pedagogy of Universidade Federal do Parana (UFPR), during the year of 2016. The research carried out investigated whether the right of childhood education of children from 0 to 3 years old that is been effected in the Municipal Education Center of the city of Curitiba. In order to find out how the vacancy prioritization policy occurs, a field study was carried out at a Municipal Center of Children Education, with the follow-up of board meetings, in which the prioritization of vacancies was discussed, besides documental analysis of the regiment, statute and minutes of the school council. A first conclusion is that the county does not answer to all demand for vacancies to children from 0 to 3 years old. To fill the few existents vacancies, the council of Municipal center of children education, through the criteria of priorization, selects some children according to guidelines of the regiment and the circular letter sent by the Municipal Department of Education in the beginning of the school year.

Keywords: Nursery; Right to Education; Priorization of vacancies; Social inequality.

\footnotetext{
1 Graduanda em Pedagogia em Universidade Federal do Paraná. E-mail: mverissimo95@gmail.com

2 Doutora em Estudos da Criança pela Universidade do Minho-PT. Professora no DTPEN - Departamento de Teorias e Prática de Ensino da Universidade Federal do Paraná. E-mail: angelamscoutinho@gmail.com
} 


\section{Introdução}

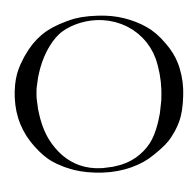

acesso à educação infantil é um direito de todas as crianças de 0 a 5 anos, firmado na Constituição Federal (1988), no Estatuto da Criança e do Adolescente (1990) e na Lei de Diretrizes e Bases da Educação 9394 (1996) e, enquanto direito público subjetivo, deve ser assegurado a todas as crianças com o devido planejamento de verbas e de comprometimento do setor público com uma educação pública, gratuita e de qualidade.

No entanto, no município de Curitiba a Secretaria Municipal de Educação (SME) admite sua incapacidade de atender toda a demanda manifesta e encaminha a cada início de ano letivo um ofício circular, no qual caracteriza quais são os critérios para priorização de vagas nas instituições de educação infantil. Também presente no regimento do CMEI, a seleção das crianças priorizadas é de responsabilidade do conselho escolar.

Nesse sentido, o estudo ora apresentado tinha como objetivo investigar se o direito a educação infantil para as crianças de 0 a 3 anos está sendo assegurado no município de Curitiba. E, a partir da análise de documentos orientadores, participação em reuniões do conselho escolar e análise de atas, observar quais são os critérios para priorização de vagas no interior da instituição e de que forma são considerados no momento da seleção.

\section{O direito à creche}

A infância não acontece de forma única a todas as crianças, há uma multiplicidade de infâncias. Intermediada por relações geracionais, de gênero, de classe, de raça, pela mídia, pela família e por diversas outras relações sociais, tem-se diversas perspectivas em torno da infância em uma mesma sociedade. Segundo Nunes e Corsino (2012, p.14): “A infância, enquanto categoria social, tem suas condições de existência diretamente vinculadas às transformações das vidas cotidianas, da estrutura familiar, da escola e da própria mídia, potente instrumento a conferir-lhe significados".

Com a Constituição Federal (CF) de 1988, Estatuto da Criança e do Adolescente (ECA) de 1990 e a Lei de Diretrizes e Bases da Educação Nacional (LDB) de 1996, a criança é percebida como sujeito social de direitos. Ocorre então o que Fullgraf (2001) denomina de infância de papel, pois apesar do reconhecimento na legislação dos direitos das crianças, não ocorre a efetivação das leis através da política. Com isso, muitas crianças vivem em situações adversas, sofrendo desde abuso sexual à exploração do trabalho infantil.

A pesquisadora Natália Soares (1997) apresenta uma análise da evolução dos direitos das crianças. Constata que a partir do século XVI há uma mudança na relação adulto criança, em que antes o núcleo 
familiar exercia pleno poder sobre as crianças e, a partir de então, surgem mudanças quanto ao estatuto e posição das crianças em relação aos adultos.

O século XIX marca a infância enquanto uma categoria social. O início do século XX é marcado pela concepção de que as crianças são o futuro da humanidade. A inglesa Eglantine Jebb foi precursora do movimento em defesa dos direitos das crianças. O movimento internacional resultou na $1^{\circ}$ Declaração dos Direitos das Crianças. A declaração de Genebra em 1923.

Em 1946, após a guerra mundial, é criado o Fundo das Nações Unidas para a infância, UNICEF. Após a aprovação em 1948 da Declaração universal dos direitos do homem, os países sentiram necessidade de um conjunto de direitos específicos para a infância. Foi então promulgado em 1959 a declaração universal dos direitos das crianças e adotada por unanimidade pela assembléia geral das nações unidas.

Em 1989 a "Convenção dos Direitos das Crianças" é promulgada. A partir disso, legislações são implementadas, como foi o caso do ECA (1990), com inspirações na convenção. Porém, apesar da luta social por direitos e da sua declaração, a desigualdade no acesso vem aumentando.

Um dos direitos básicos das crianças é a educação. A educação infantil foi muito tempo relacionada a práticas assistencialistas, preparatórias ou compensatórias, em que crianças pobres tinham acesso a uma educação pobre. A creche no Brasil, representa ainda hoje, nos discursos oficiais e nas práticas existentes, dois pólos, um com vínculo assistencial para crianças pobres, outro como conquista do movimento popular e das reivindicações dos movimentos feministas, com aposta de um atendimento de qualidade. As instituições pensadas para crianças ainda revelam resquícios de ambiguidades no que diz respeito à classe social. Como afirmam Nunes e Corsino (2012, p. 19) "Entretanto, é no decorrer desse processo de institucionalização, na emergência da criança pública, que também vão se formando movimentos em defesa dos direitos da criança".

Sob a égide de movimentos populares e de novas concepções de criança e infância, são proclamadas algumas leis que visam incorporar o discurso do direito à educação para as crianças pequenas.

A LDB 9394/96 inova no sentido de tornar a educação infantil uma etapa da educação básica, sendo desvinculada da ideia de assistência social. Apesar disso, ela não garante financiamento específico para a educação infantil.

Movimento semelhante ocorre em relação à implementação do ECA (1990), que é definido a partir do reconhecimento da criança como ser social, com ênfase na necessidade de ser protegido e amparado, porém o estatuto sofre os impactos da sociedade de classes, não sendo executado da forma desejada.

O direito à educação deve responder ao princípio de igualdade de oportunidade para as classes sociais, os sexos, as raças e os credos. Apesar de ser direito das crianças o acesso à educação infantil, por problemas de gestão e financiamento, não há vagas para todas elas. Devido a isso, são criados critérios de seleção para o ingresso na instituição. 


\section{O direito à Educação Infantil}

O fato de haver critérios de seleção para a entrada na instituição de educação infantil cria situações de acusações, além de competitividade e individualidade entre a comunidade. Há ainda as fraudes no processo, em que famílias aflitas por vagas chegam a falsificar comprovantes de renda e moradia, como aponta Fullgraf (2001) em sua pesquisa.

Os conselhos tutelares e o ministério público atuam no sentido de garantir o direito das crianças de 0 a 5 anos à educação infantil. Com ações coletivas ou individuais, as famílias que têm o direito violado procuram uma solução ao seu problema.

Aos conselhos de direitos e aos conselhos tutelares é relegada a função de garantir o que está no ECA, porém, devido as prioridades do governo com políticas neoliberais de desobrigação do Estado com políticas públicas, fica dificultada a efetivação dos direitos.

A partir de 2006 o ministério da Educação regulamentou a lei n. 11.274 que institui o ensino fundamental de nove anos de duração. "O ensino fundamental obrigatório, com duração de 9 (nove) anos, gratuito na escola pública, iniciando-se aos 6 (seis) anos de idade, terá por objetivo a formação básica do cidadão" (ART. 32). Especificando assim a obrigatoriedade do poder público em: "recensear os educandos no ensino fundamental, com especial atenção para o grupo de 6 (seis) a 14 (quatorze) anos de idade e de 15 (quinze) a 16 (dezesseis) anos de idade” (ART. 87). A lei dispõe também sobre a inclusão das crianças de 6 anos de idade no ensino fundamental "I - matricular todos os educandos a partir dos 6 (seis) anos de idade no ensino fundamental" (ART. 87).

O Plano Nacional de Educação (PNE) determina diretrizes, metas e estratégias para a política educacional dos próximos dez anos. A Emenda Constitucional n59/2009 mudou a condição do PNE, que passou de uma disposição transitória da LDB 9394/96 para uma exigência constitucional com periodicidade decenal e passou a ter previsão do Produto Interno Bruto (PIB) para seu financiamento.

Em um país com gritante desigualdade social, para que haja efetivação de metas e estratégias do PNE que busquem equidade de oportunidades e qualidade da educação é necessário que haja políticas públicas de Estado que garantam a efetivação de direitos.

A meta 1 do PNE se refere à universalização da educação infantil na pré-escola para as crianças de quatro e cinco anos e a ampliação da oferta de educação infantil em creches de forma a atender, no mínimo, 50\% das crianças de zero a três anos.

Na questão de financiamento para a efetivação dessa meta, a educação infantil foi incorporada à educação básica como medida de política pública e passou a contar com o Fundo de Manutenção e Desenvolvimento da Educação Básica e de Valorização dos Profissionais da Educação (FUNDEB), a partir de 2007. Outra medida foi a emenda constitucional $n^{\circ} 59$ de 2009 que estendeu a obrigatoriedade do ensino às crianças de 4 a 17 anos. Uma obrigatoriedade que induz a oferta. Devido ao pacto federativo, a Constituição de 88 no seu artigo 30 se refere à responsabilização do município pela oferta da educação infantil em regime de cooperação da União e dos estados. Devido a descentralização de responsabilidades, 
o município de Curitiba é responsável pela oferta da educação infantil. Os entes federados foram obrigados a garantir a efetivação desse direito às crianças de 4 e 5 anos até o ano de 2016.

O site "planejando a próxima década" do Ministério da Educação (MEC), utiliza dados do Instituto Brasileiro de Geografia e Estatística (IBGE) como a Pesquisa Nacional por Amostra de Domicílios Contínua (PNAD-2015) para índices referentes ao Estado, Região e Brasil e dados do Censo Populacional (2010) para índices referentes ao município. Os indicadores presentes no site indicam que o município de Curitiba encontra-se acima da média nacional de população de 0 a 3 anos que frequenta a instituição de educação infantil. A meta do PNE é atingir 50\% das crianças dessa faixa etária atendidas ao final da vigência do plano, em 2024. No momento, o Brasil atende apenas 30,4\% das crianças de 0 a 3 anos. Curitiba está com 44,8\% de crianças frequentando a creche, segundo os dados disponíveis no site.

Mesmo com grande probabilidade de atingir a meta até 2024, a quantidade de crianças excluídas das instituições de educação infantil continua sendo muito elevada. Segundo site da Prefeitura de Curitiba, o governo federal custeou $50 \%$ dos gastos com novos CMEI's através do programa Proinfância ${ }^{3}$, com o restante sendo financiado pelo orçamento municipal, chegando a 22 o número de CMEI’s concluídos ou em construção. Quanto aos já construídos, alguns não estão em funcionamento devido a falta de recursos para o pagamento e contratação de novos profissionais para atuar na área.

Segundo dados do site da Prefeitura de Curitiba, no ano de 2016, o investimento em educação na rede municipal de Curitiba foi ampliado de $25 \%$ para 30\% das receitas utilizadas para calcular o mínimo constitucional para a área. Apesar de haver recursos do FUNDEB advindos do regime de colaboração, da parcela do PIB destinado à educação e da ampliação dos investimentos na área, o financiamento ainda é insuficiente para a manutenção da ampliação e da qualidade. Soma-se a isso a necessidade de levantar dados mais precisos para a efetivação desse direito, as fontes de financiamento e a distribuição desses recursos.

A real demanda por educação infantil fica oculta quando observamos apenas a demanda explícita, conforme Rosemberg (1999) denomina, que é o número de matrículas realizadas na instituição de educação infantil. Em contraponto, não existe nenhuma forma de análise no Brasil da demanda latente, que é a demanda não manifesta, devido a diversos fatores, como distância entre o domićlio e a instituição, qualidade ou tipo de serviço oferecido etc.

Segundo notícia veiculada no dia 15/12/15 na plataforma online do jornal Gazeta do Povo, para atender a meta de universalizar a educação às crianças de 4 e 5 anos, a prefeitura de Curitiba utilizou como estratégia o fechamento de turmas de berçário, que atendem crianças de até um ano e meio. A crise econômica agrava a situação, com menor arrecadação de impostos, o município possui menores condições de investimento. Além disso, também aumenta a procura de vagas em instituições públicas.

3 O Programa Nacional de Reestruturação e Aquisição de Equipamentos para a Rede Escolar Pública de Educação Infantil (Proinfância) foi criado pelo governo federal em 2007 e é parte das ações do Plano de Desenvolvimento da Educação do Ministério da Educação (PDE MEC). O seu principal objetivo é prestar assistência financeira ao Distrito Federal e aos municípios, visando garantir o acesso de crianças a creches e escolas de educação infantil da rede pública. 
Privadas dos benefícios pessoais, educacionais, econômicos e sociais que a educação infantil oferece, resta às crianças, programas de baixa qualidade, que segundo Choi (2004) não causam muito impacto. Ou ficar em casa a maior parte do tempo, sem contato com outras crianças e sem adultos com formação específica para sua educação e cuidado. Como nos aponta Nunes e Corsino (2012, p.29): “A nova institucionalidade da infância implica, necessariamente, a qualidade do atendimento".

Uma educação infantil de qualidade se faz com investimento e uma gestão adequada às especificidades das crianças. Com tempos e espaços que as respeitem e dêem a possibilidade de que sejam ouvidas plenamente.

Diante destas constantes violações, a questão que se coloca é: a população, as comunidades, as famílias precisam aprender a ser sujeito de negociação e precisam articular a luta de forma coletiva, tornando-se um desafio o papel dos movimentos sociais de luta pelo direito da nova ordem social (FULLGRAF, 2001, p. 114).

É preciso que a comunidade se engaje na luta por seus direitos e que haja uma conscientização a respeito da importância e valorização da educação infantil no desenvolvimento pleno das crianças para além das necessidades concretas e reais das famílias pelas vagas. A educação também é importante aliada na luta contra a desigualdade social existente no país, facilitando o princípio de justiça social.

A igualdade de oportunidades na educação é princípio importante de justiça social, tendo sua origem no combate aos privilégios de hereditariedade, sexo, nacionalidade, origem étnica ou regional, rendimento econômico como obstáculo para o acesso à educação, como foi característica durante muitos séculos na história da humanidade (COUTINHO; SILVEIRA, 2016, p. 79).

Para além da questão do acesso, é preciso que haja também a garantia de um padrão de qualidade. A CF prevê em seu artigo 206 a qualidade da educação como um princípio constitucional. Ximenes (2014) faz uma crítica ao mínimo existencial como padrão de qualidade.

Mas não é do "mínimo" que se parte para a construção dos conteúdos dos direitos fundamentais, nem é do "mínimo" o que se almeja em termos de desenvolvimento e direitos humanos. Disto a emergente e complexa questão da qualidade da educação básica como um direito é uma das maiores provas. (XIMENES, 2014, p. 124)

Ximenes (2014) também aponta os entraves no campo do direito referentes à jurisprudência e a dimensão subjetiva dos direitos prestacionais. Como é o caso da vedação do retrocesso social. No caso da universalização da pré-escola para crianças de 4 e 5 anos, a prefeitura de Curitiba optou pelo fechamento de turmas de berçário, na jurisprudência, isso pode ou não caracterizar retrocesso social, pois de certa forma ampliou o atendimento a uma faixa etária. Mas, nesse caso cabe uma questão: como ficam as crianças de 0 a 3 anos que estão fora da creche?

\section{Caminhos Metodológicos da Pesquisa}

Para o desenvolvimento do estudo foi realizada uma revisão de literatura acerca dos temas: Institucionalização da infância e direito a Educação e um estudo de caso em um Centro Municipal de 
Educação Infantil (CMEI) de Curitiba, com análise documental e observação de uma reunião de conselho do CMEI, a fim de investigar quais eram os critérios de priorização de vagas do município e se no interior do CMEI eram seguidas as orientações da Secretaria Municipal de Educação.

No final do ano de 2015 foi enviada uma carta de apresentação e realizada uma visita a instituição para apresentar o projeto e solicitar a aprovação para participar das reuniões do conselho escolar. No início do ano de 2016 foi feito contato novamente para solicitar a data da reunião e foi informado que aconteceria no final do mês. Dias antes da data, foi realizado novamente contato para confirmar e foi comunicado pela instituição que a reunião já havia acontecido no início do mês. Ao notar este entrave, novamente foi realizada uma visita à instituição para apresentar a pesquisa e participar da reunião seguinte. Não informaram sobre a data da próxima reunião, que ocorreu três dias depois que estivemos presentes no CMEI. Foram realizadas três reuniões ao longo do período da pesquisa, foi possível participar de apenas uma, mesmo entrando frequentemente em contato com a instituição. Foi realizada também uma análise documental de atas, regimentos e estatutos do conselho e do CMEI, mas também houve dificuldade de acesso aos documentos.

A participação nas reuniões caracterizaria a melhor forma de investigar as percepções dos envolvidos na priorização de vagas, visto que as questões subjetivas presentes não constam nos documentos escritos.

Sobre o estudo de caso e as dificuldades encontradas no decorrer da pesquisa:

É o momento de especificar as questões ou pontos críticos, de estabelecer os contatos iniciais para entrada em campo, de localizar os informantes e as fontes de dados necessárias para o estudo. Essa visão de abertura para a realidade tentando captá-la como ela é realmente, e não como quereria que fosse, deve existir não só nessa fase, mas no decorrer de todo o trabalho, já que a finalidade do estudo de caso é retratar uma unidade em ação (ANDRÉ, LUDKE, 2013, p. 25).

Os entraves no acesso aos documentos e participação nas reuniões demonstram as barreiras e limitações do estudo de caso, que apesar de desvelar a realidade, nem sempre é possível obter a totalidade das informações.

A pesquisa foi realizada em um CMEI de Curitiba, em um bairro que tem uma população de 13.189 habitantes. A média salarial da população residente no bairro em que foi realizada a pesquisa é de mais de $1 / 2$ a 2 salários mínimos, segundo o censo de 2010. O rendimento médio de homens é de $\mathrm{R} \$ 1.529,21$ e de mulheres $\mathrm{R} \$ 853,05$. Há uma carência de equipamentos de saúde, educação e cultura e possui 12 áreas de ocupação irregular, com 3.557 habitantes nessas áreas. O CMEI fica situado em uma das áreas de ocupação irregular, porém já regularizada pela prefeitura. Conta com apenas dois Centros Municipais de Educação Infantil e uma escola de Ensino Fundamental, com uma sala de pré-escola no turno da tarde em funcionamento. 


\section{O que dizem os documentos?}

Em busca dos critérios de priorização de vagas, tivemos como primeira fonte da pesquisa o regimento do CMEI. Em seu artigo 51 constava quais eram os critérios adotados pela instituição para a seleção das crianças priorizadas.

Art. 51 - Na efetivação das matrículas, deverão ser atendidas, após análise e referendo do Conselho do CMEI, prioritariamente:

I - crianças que se encontrem em situação de risco social e pessoal;

II - crianças cujos pais estejam trabalhando.

Parágrafo Único - A criança com deficiência terá direito à matrícula compulsória, conforme determina a Lei Federal n.o 7.853/89.

Em busca de mais informações a respeito dos critérios, foi analisado o regimento do conselho do CMEI, no qual os critérios de priorização de vagas são citados do mesmo modo que no regimento do CMEI.

É enfatizada nos documentos a responsabilidade do conselho na priorização das vagas. $\mathrm{O}$ artigo 46 do Estatuto do Conselho em seu inciso V define como atribuição do Conselho do CMEI: "Participar da análise de solicitações de matrículas em conformidade com os critérios estabelecidos no Regimento do Centro Municipal de Educação Infantil”.

O artigo 26 do Regimento do Conselho estabelece as atribuições do Conselho do CMEI. No inciso V-acompanhar o cumprimento de normas e de diretrizes da mantenedora quanto à matrícula e ao desligamento de crianças e no VI- participar da análise de solicitações de matrículas em conformidade com os critérios estabelecidos pela SME.

A Secretaria Municipal de Educação (SME) envia a cada início de ano letivo um ofício circular a cada CMEI rememorando quais são os critérios de priorização de vaga. São eles: I- crianças que se encontram em situação de risco social e pessoal; II- crianças cujos pais estejam trabalhando, considerando a menor renda per capita. Consta ainda no parágrafo único que a criança com deficiência terá direito à matricula compulsória, conforme determina a Lei Federal No $\mathrm{N}^{\circ} 783 / 89$.

O que difere do regimento do CMEI é o acréscimo de "considerando a menor renda per capita". Em conversa com a diretora da instituição, foi informado que o regimento está em fase de adaptações e que eram sempre priorizadas as orientações enviadas pela SME. No ofício a rede justifica sua incapacidade de atender toda a demanda manifesta e, por esse motivo, enfatiza que a prioridade será para as crianças que moram no município.

Consta também a necessidade de formação de uma comissão para a realização de visitas domiciliares, que priorizará a participação dos representantes da unidade de saúde local e de instituições comunitárias, quando possível. A visita é constituída por observação e registro em ficha própria, atentando às condições de moradia, situação da criança, quem cuida, dentre outros.

No caso do CMEI campo da pesquisa, quem realiza a visita é uma técnica administrativa e uma professora, observam todos esses pontos e anotam em ficha própria que é disponibilizada no momento da reunião do conselho para apreciação dos demais representantes. 
No ofício consta que "o registro da ata deverá constar o nome completo da criança, a turma em que será matriculada e os motivos que levaram a destinação da vaga para a criança". Porém, ao observar a ata, não foi encontrado os motivos que levaram a destinação da vaga em nenhum dos registros.

\section{Famílias, instituição e vulnerabilidade}

$\mathrm{Na}$ reunião do conselho foco da presente análise, foi indicado que a mãe da criança que foi priorizada havia ido ao CMEI várias vezes chorando e implorando pela vaga. A renda per capita da família é de $\mathrm{R} \$ 201,00$ e a criança fica no trabalho com a mãe. A professora representante que estava presente na reunião afirmou que: quem realmente precisa corre atrás, se esforça para conseguir a vaga, como era o caso dessa mulher. Tem uns que nem fazem tanto esforço, dai fica dificil.

A partir de tal posicionamento, os conselheiros entraram em um debate acerca do fato da vaga ser destinada aos mais pobres, conforme as falas abaixo:

\section{Se a mãe ganha bem ela lutou por isso, ela também deveria ter direito a vaga, porque paga os impostos, não é justo só os pobres ficarem com a vaga; \\ Mas se é direito da criança, não deveria importar se épobre ou rico.}

Questionaram também como garantem que a familia é pobre. Nesse ponto, a diretora disse que pela visita se garante a veracidade da informação e que as pessoas não costumam mentir, ela ainda argumentou que havia família que a mãe declarou receber quatro ou cinco mil de salário e mesmo assim estava na espera pela vaga.

Mesmo com esta afirmação, em outro momento, quando foi questionada se as famílias poderiam saber quais eram os critérios de priorização de vagas a diretora informou que isso deveria ser mantido em sigilo, pois algumas famílias, segundo ela, poderiam tentar forjar as situações para que fossem priorizadas. Tal perspectiva entra em conflito com o que o ofício circular da SME enfatiza: "Ressaltamos ainda que os procedimentos para o preenchimento de vagas devem ser compartilhados com todos os funcionários e famílias/responsáveis para que estejam cientes do conteúdo do Regimento”.

Para observar a situação de vulnerabilidade das famílias duas representantes do conselho realizam visitas nas casas. Foram relatadas questões de estrutura, como casas com entulhos, materiais de construção, ratos e esgoto a céu aberto. O que impede a exploração do espaço domiciliar pelas crianças, além de haver explícito risco para elas. Além disso, duas crianças ficam em creches comunitárias, segundo as conselheiras, apenas com a perspectiva de cuidado, sem intuito educativo. Muitas vezes estes são os únicos ambientes de convívio dessas crianças, quando não dispõem de acesso a creche e pré-escola ou outras redes de apoio.

A educação infantil é, muitas vezes, a única alternativa para a educação e cuidado das crianças de famílias que se encontram em situação de pobreza, fenômeno que desestrutura relações e as condições de vida das famílias. É urgente pensar na implementação de programas sociais, que devem ser intersetoriais e tenham as famílias como foco de políticas públicas eficazes. 
É imprescindível ter em mente que esse sistema de desigualdade e má distribuição de renda destrói não só as famílias, mas toda a sociedade. Percebe-se, na verdade, que a questão fundamental é a necessidade de promoção e apoio às famílias vulneráveis através de políticas sociais bem articuladas e focalizadas. O reconhecimento das mesmas, como objeto de políticas públicas, constitui fator decisivo para atingir objetivos prioritários do desenvolvimento humano, tais como a minimização da pobreza, o acesso à educação, saúde, alimentação, moradia e proteção integral às suas crianças e adolescentes (GOMES; PEREIRA, 2005, p. 361).

Cabe ressaltar a necessidade de maior esclarecimento conceitual, devido ao equívoco que constitui a ideia de risco e vulnerabilidade, muitas vezes caracterizados como sinônimos. Tanto o regimento como o ofício da SME não esclarecem os conceitos, ficando a cargo dos representantes do conselho definirem o que julgam ser risco e vulnerabilidade, de forma bastante subjetiva.

A abordagem de Janczura (2012) demonstra que risco refere às condições fragilizadas da sociedade tecnológica contemporânea, enquanto vulnerabilidade identifica a condição dos indivíduos nessa sociedade.

Foram Yunes e Szymanski (2001) que chamaram atenção para a diferença entre os conceitos de risco e vulnerabilidade. Segundo elas, o conceito de vulnerabilidade "é aplicado erroneamente no lugar de risco" (p. 29) pois são dois conceitos distintos. Enquanto risco, segundo as autoras, foi usado pelos epidemiologistas em associação a grupos e populações, a vulnerabilidade refere-se aos indivíduos e às suas suscetibilidades ou predisposições a respostas ou consequências negativas. (JANCZURA, 2012, p. 302)

Partindo dessa perspectiva, é questionável a adoção do termo risco no caso dos critérios de priorização de vaga, pois mesmo a falta de vaga na instituição já caracteriza um fator de risco para a criança.

A noção de risco implica não somente iminência imediata de um perigo, mas também a possibilidade de, num futuro próximo, ocorrer uma perda de qualidade de vida pela ausência de ação preventiva. A ação preventiva está relacionada com o risco, pois não se trata de só minorar o risco imediatamente, mas de criar prevenções para que se reduza significativamente o risco, ou que ele deixe de existir (JANCZURA, 2012, p. 306)

No mês de março, na primeira reunião do conselho para priorização de vaga, havia 40 solicitações para 14 vagas no berçário (para crianças de até um ano). No maternal I (crianças de um a dois anos) havia 15 solicitações para 6 vagas. No MII (crianças de dois a três anos) havia 12 solicitações para 6 vagas. No pré I (crianças de três a quatro anos) havia 8 vagas e 3 solicitações. No pré II (crianças de quatro a cinco anos) havia 4 solicitações para 6 vagas. Essa "sobra" de vagas no pré ocorreu devido ao fechamento de turmas de berçário e maternal que houve no CMEI para atender a universalização do atendimento até o fim do ano de 2016.

$\mathrm{Na}$ reunião do conselho sobre a priorização de vaga - foco principal de análise, havia ainda vinte e oito solicitações de vagas e apenas 4 vagas para o berçário. No maternal I não havia vaga disponível, por isso não chegaram a contar quantas crianças estavam à espera. No maternal II havia cinco solicitações de vaga e apenas uma vaga disponível, que foi prontamente destinada à criança que fica aos cuidados do pai, 
que é tóxico dependente. O pré I tinha 4 vagas em aberto e não havia demanda. O pré II tinha 2 vagas em aberto e também não havia demanda.

A diretora havia selecionado previamente três crianças para as vagas do berçário, consideradas em situação de vulnerabilidade. Motivos:

- Mãe trabalha de diarista, o pai é tóxico dependente e a criança fica aos cuidados de uma tia de 14 anos, que havia realizado uma cirurgia há pouco tempo.

- Criança fica aos cuidados da avó doente de 65 anos.

- Criança que fica aos cuidados de uma avó idosa e surda, quando a criança chora ela não a atende.

Os representantes do conselho concordaram que essas crianças estariam em situação de vulnerabilidade. Ao restar uma vaga, observaram o critério seguinte, crianças cujos pais estejam trabalhando, considerando a menor renda per capita.

Foi realizada outra reunião três dias depois (a qual não nos foi informada), isso porque a diretora identificou que uma das crianças priorizadas no berçário já estava matriculada em outro CMEI.

Nesse processo de priorização os representantes do conselho observavam apenas se a figura materna trabalhava e a menor renda entre elas. Entre os selecionados haviam pais desempregados, mas mães desempregadas não eram priorizadas. A tendência predominante acaba sendo a delegação do cuidado à figura feminina, pois a compreensão é que caso não tenha vaga, consequentemente a criança ficará com a mãe.

No entanto, mesmo caracterizando os pais como educadores e considerando as citadas transformações familiares, a mãe permanece como figura que desempenha um papel de mantenedora da afetividade familiar, sendo que a ela cabe a responsabilidade pelo cuidado e educação dos filhos, dentro do lar e fora dele (SAMBRANO, 2010, p. 145).

Havia casos de mães que alegaram não trabalhar justamente por não ter para quem delegar o cuidado da criança, porém esses casos não entraram na seleção. Após todas as fichas lidas e selecionadas a partir desse critério, fizeram a contagem da menor renda per capita. Outra questão relevante é a caracterização de uma família nuclear nesses critérios, um modelo de família muitas vezes considerado como ideal.

Esse modelo de família apresenta como características uma estrutura pautada na hierarquia, divisão sexual do trabalho, vínculo afetivo e controle da sexualidade feminina. Em outras palavras, trata-se de uma família monogâmica, composta de pai, mãe e filhos que se amam e se respeitam intensamente, sendo que ao pai cabem o sustento e a satisfação de todas as necessidades familiares através de seu trabalho, à mãe cuidar da casa e dos filhos, protegendo-os e educando-os de acordo com as regras da moral, bons costumes e higiene, sempre de maneira carinhosa e infatigável, às crianças, crescer, brincar e estudar, com alegria e despreocupação, num ambiente estável e harmônico, onde predominam a lealdade, proteção, amor e respeito. (MACEDIM 1994; MELLO, 2000; ROMANELLI, 2000 apud SAMBRANO, 2010, p. 142)

O movimento feminista incidiu na renovação de valores e crenças acerca da condição da mulher, com a sua inserção no mercado de trabalho, aconteceram muitas mudanças na rotina familiar, sendo 
assim, as crianças precisam estar sob o cuidado de outros adultos, em especial nas instituições de educação infantil.

O direito à educação infantil é um direito também das famílias, que necessitam de um espaço complementar de cuidado e educação de seus filhos. Conforme consta na Constituição Federal de 1988:

Art. $7^{\circ}$ São direitos dos trabalhadores urbanos e rurais, além de outros que visem à melhoria de sua condição social: XXV - assistência gratuita aos filhos e dependentes desde o nascimento até 5 (cinco) anos de idade em creches e pré-escolas; (Redação dada pela Emenda Constitucional no 53 , de 2006).

Além do direito a vaga na instituição, as famílias também têm o direito a participar da construção e tomada de decisões nesse contexto, efetivando assim o direito a uma educação democrática.

\title{
Gestão democrática e o papel do conselho escolar
}

Além de definição teórica, a gestão democrática também é um princípio constitucional e a LDB também o reafirma.

Desta forma, não é uma escolha deste ou daquele ente federado ou da escola a democratização da gestão. O Conselho de Escola é o instrumento que operacionaliza a gestão democrática das escolas, por isso órgão de suma importância. No entanto, a gestão democrática muitas vezes coloca em questão situações enraizadas nos processos escolares, como a centralidade do poder (FERRAZ; FINATTI, 2015, p. 112).

O Brasil passou por um longo período em que o povo não participava ativamente da vida pública e política. Segundo Freire (1999) a experiência exacerbada de autoritarismo gerou uma inexperiência democrática e uma ausência de consciência comunitária no povo brasileiro:

\begin{abstract}
Entre nós, pelo contrário, o que predominou foi o mutismo do homem. Foi a sua nãoparticipação na solução dos problemas comuns. Faltou-nos, na verdade, com o tipo de colonização que tivemos, vivência comunitária. Oscilávamos entre o poder do senhor das terras e o poder do governador, do capitão mor. A própria solidariedade aparentemente política do homem ao seu senhor, ao proprietário das terras, quando essa solidariedade se fez necessária com a importação da democracia política, era, antes de tudo, uma solidariedade aparentemente política. É que em todo o nosso background cultural, inexistiam condições de experiência, de vivencia da participação popular na coisa pública. Não havia povo (FREIRE, 1999, p.78).
\end{abstract}

Freire (1999) afirma que a democracia só se aprende experienciando e acredita que apesar de todo o hábito antigo e culturológico de passividade, é possível transgredir esse passado e a partir de novos hábitos de participação e ingerência seria possível a criação de novas disposições democráticas.

Na busca de transgredir esse passado de não participação, o conselho dentro do ambiente escolar constitui um espaço de troca e reflexão entre os membros envolvidos, proporcionando uma experiência democrática aos envolvidos. 
As reuniões de conselho da escola também refletem um espaço e momento de relacionamento no que tange à gestão escolar, na medida em que temos os pais envolvidos com a tomada de decisões da instituição, como membros de conselho ou sistemas administrativos escolares (SAMBRANO, 2010, p 151).

No entanto, compreende-se o caráter político e dialógico da educação democrática, com o fato da participação ser provocada, não se pode admitir que seja dirigida ou manipulada.

Na reunião do conselho do CMEI os representantes pouco ou nada opinaram sobre a priorização de vagas. A diretora já iniciou a reunião com os pré-selecionados e não houve questionamento ou discussão a respeito da seleção previamente realizada.

Nesse sentido, diversos estudos têm mostrado que a "gestão democrática" da escola pública no Brasil, na maioria das vezes, tem se limitado: a um movimento de centralização da tomada de decisão nas políticas públicas pelos órgãos gestores e da descentralização da execução pelas escolas de tarefas pré-determinadas; à eleição do diretor, que, em decorrência de diversos fatores, dirige a escola de forma muitas vezes centralizada e centralizadora; à formação de conselhos escolares que se reúnem ocasionalmente apenas para referendar as decisões previamente tomadas pelo diretor ou porque a formalidade burocrática assim o exige [...] (SOUZA, 2012, p. 181).

A representante das famílias não emitiu nem foi incentivada a emitir opinião durante toda a reunião. Admitia-se, assim, uma não participação.

Assim, é preciso compreender se a atividade desenvolvida pela comunidade na escola envolve algum nível de "partilha de poder", ou trata-se de uma atividade de colaboração para com a execução de atividades previamente definidas pela direção. Nesse último caso, a participação pode traduzir-se em uma relação passiva, como por exemplo, na atividade de um tarefeiro (SOUZA, 2012, p. 180).

A gestão democrática no ambiente escolar é muitas vezes regida pela democracia representativa, o conselho é um exemplo disso. Conforme Souza (2012, p. 184) "Para uma democracia de massas, a participação ativa da comunidade deve ocorrer em instâncias deliberativas da escola (como o conselho escolar ou equivalente), em reuniões pedagógicas e mesmo em processos de formação" A participação no processo de decisão no CMEI corrobora com a ideia de "partilha do poder".

Ainda outro ponto a ser tocado e mudado é o fato de que em muitos sistemas o diretor da escola é o presidente nato do conselho escolar da escola a qual dirige. Afinal não se pode querer democratizar algumas instâncias e outras não. É preciso ter coerência (SOUZA, 2012, p.185).

No CMEI, a diretora é a mesma desde a inauguração e é presidente nata do conselho. Isso é justificado devido ao fato do município de Curitiba não possuir legislação de gestão democrática. Ferraz e Finatti (2015) apontam que o Conselho Municipal de Educação (CME), apesar de existir desde 1985 ainda não tem deliberado nada acerca dos conselhos escolares. Enquanto não há normas vigentes, o Sistema Municipal de Educação (SISMEN) adota as normas complementares do Conselho Estadual de Educação (CEE). No entanto, como ainda não há deliberação do CME e nem lei municipal sobre o assunto, o município segue uma deliberação do Conselho Estadual de Educação (Deliberação 16/99) que determina em seu texto que "a diretora da escola é membro nato do conselho e ocupa a presidência do mesmo" 
(FERRAZ; FINATTI, 2015, p 116). A representatividade de todos os seguimentos da comunidade escolar caracteriza um importante quesito no que se refere a democratização do conselho escolar.

Como afirmado, os Conselhos Escolares têm autonomia quanto à deliberação dos segmentos que o compõe. No entanto, a Secretaria Municipal de Educação (SME) orienta que essa escolha por parte dos colegiados respeite o princípio de paridade, mantendo igual número de representantes da escola e da comunidade, seguindo a deliberação n016/99 do Conselho Estadual de Educação que trata essa situação indicando o "equilíbrio entre os seguimentos" (FERRAZ; FINATTI, 2015, p. 118).

O regimento do conselho estabelece a constituição dos conselheiros, de acordo com o princípio de paridade:

Art. 12 - O Conselho do Centro Municipal de Educação Infantil será constituído pelos seguintes conselheiros titulares e respectivos suplentes: Diretor- presidente; 1 representante (s) do suporte técnico pedagógico; 1 representante da equipe administrativa (agente e apoio administrativo); 1 representante dos docentes; 2 representantes dos pais/ responsáveis da diretoria da APPF; 3 representantes dos pais/responsáveis pelas crianças; 1 representante da Unidade de Saúde; 1 representante de instituições comunitárias (de acordo com a realidade local); Parágrafo Único - Os conselheiros titulares e suplentes serão eleitos, atendendo as normas previstas no Estatuto do Conselho do CMEI.

$\mathrm{Na}$ reunião observada estavam presentes os respectivos representantes: a diretora, a pedagoga, duas professoras de educação infantil, uma professora do magistério, uma agente administrativa, uma representante das famílias e um representante do núcleo regional.

Em análise das atas das demais reuniões verificou-se que no dia 15/04 estavam presentes a diretora, a pedagoga, duas professoras da educação infantil, uma professora do magistério, a agente administrativa, uma representante das famílias e um representante da unidade de saúde.

No dia 07/03 estavam presentes a diretora, a pedagoga, três professoras de educação infantil, um agente administrativo, duas responsáveis da Associação de pais, professores e funcionários (APPF), duas representantes das famílias, um representante da unidade de saúde e um representante do núcleo regional.

Assim, observa-se que em apenas uma reunião houve paridade entre os representantes. Além disso, na reunião observada, não ocorreu a participação ativa da mãe que estava presente, pois não manifestou sua opinião ou interveio em momento algum.

Outro ponto a ser analisado é que em todas as reuniões, na representação das famílias havia apenas a participação das mães. Ao observar as atas de outras reuniões realizadas pelo conselho pode-se constatar que a presença masculina encontrava-se apenas na figura do agente da unidade de saúde e no representante do núcleo regional.

\section{Considerações finais}

Em um país tão desigual, com riquezas tão mal distribuídas, é ainda mais necessário garantir a efetivação dos direitos sociais. Além da distribuição de renda, outro fator de perpetuação de desigualdade 
social é a educação, pois famílias que não conseguem oferecer uma educação de qualidade aos seus filhos e às suas filhas, perpetuam um ciclo de pobreza. É preciso garantir que além do acesso, as crianças tenham possibilidade de frequentar espaços com excelente padrão de qualidade, com oportunidades de aprendizagem, infraestrutura e bons profissionais que garantam seu desenvolvimento integral.

Com a obrigatoriedade da universalização da pré-escola até o presente ano, o município adotou a política de fechamento de berçários. Com isso, houve um aumento da demanda não atendida. As famílias que mais sofrem com essa falta de planejamento e ineficiência do Estado são as famílias pobres, pois dependem integralmente das políticas públicas. Com a falta de vagas, são obrigadas, muitas vezes, a deixar suas crianças aos cuidados de vizinhos, instituições não formais ou parentes, espaços que podem não propiciar experiências ricas em possibilidades de aprendizagem às crianças, além de colocá-las em situações de risco.

O Estado atesta mais uma vez a sua ineficiência quando prevê a necessidade de haver critérios para priorização de vaga, revela sua ineficácia em atender um direito social tão importante para a redução da desigualdade social que é a educação. A necessidade de haver critérios de priorização de vagas aponta um caráter assistencialista, teoricamente já superado da educação infantil. A educação é direito de todos, independentemente de classe social ou renda.

Porém, diante do atendimento insuficiente, é necessário que os critérios garantam o princípio de justiça social (COUTINHO; SILVEIRA, 2016), com critérios específicos que delimitem melhor os conceitos de risco social, vulnerabilidade, família com menor renda per capita, com vistas a redução da desigualdade social. Assim, faz-se necessário maior clareza em relação aos critérios, pois acabam sendo muito generalistas, dificultando a análise e seleção por parte dos representantes do conselho, que acabam analisando de maneira muito subjetiva. 


\section{Referências}

ANDRÉ, Marli; LUDKE, Menga. Pesquisa em educação: abordagens qualitativas. Rio de Janeiro: Editora EPU, 2013, p. 20-44.

BRASIL. Constituição da República Federativa do Brasil de 1988. Presidência da República, Casa Civil, 2006. Disponível em: <http://www.planalto.gov.br/ccivil_03/Constituicao/Constituicao.htm> Acesso em: 06/03/2016.

BRASIL. Emenda n 59/2006. Presidência da República, Casa Civil, 2006. Disponível em: <http://www.planalto.gov.br/ccivil_03/constituicao/emendas/emc/emc59.htm.> Acesso em: 07/03/2016

BRASIL. Estatuto da criança e do adolescente: Lei federal nº 8069, de 13 de julho de 1990. Presidência da República, Casa Civil. Disponível em: < http://www.planalto.gov.br/ccivil_03/leis/L8069.htm>. Acesso em: 06/03/2016.

BRASIL. Lei de Diretrizes e Bases da Educação Nacional. Lei n.9.394/96. Presidência da República, Casa Civil. Disponível em: <http://www.planalto.gov.br/ccivil_03/Leis/L9394.htm.> Acesso em: 07/03/2016.

COUTINHO, Angela Scalabrin; SILVEIRA, Adriana Dragone. As políticas de priorização para o acesso ao direito à educação infantil em creches. In: Revista Trama Interdisciplinar, São Paulo, v. 7, n. 2, maio/ago. 2016, p. 64-84.

CURITIBA. Centro Municipal de Educação Infantil. Regimento Interno. Curitiba, 2012.

FERRAZ, Jokasta Pires Vieira; FINATTI, Renata Riva. Conselhos escolares: desafios e participação. In: COUTINHO, Angela Scalabrin (org). Qualidade da educação: democratização do acesso, permanência, avaliação, condições de participação e aprendizagem: livro 4: CONAE Paraná: Reflexões e provocações. Curitiba: Appris, 2015, p. 109-124.

FREIRE, Paulo. Educação como prática da liberdade. Rio de Janeiro, Paz e Terra, 1999.

FÜLLGRAF, Jodete Bayer Gomes. A infância de papel e o papel da infância. Dissertação (Mestrado em Educação). Florianópolis, Programa de Pós-graduação em Educação, Universidade Federal de Santa Catarina, 2001.

GOMES, Mônica Araujo; PEREIRA, Maria Lúcia Duarte. Família em situação de vulnerabilidade social: uma questão de políticas públicas. In: Ciência e saúde coletiva. 2005. P. 357-363.

JANCZURA, Rosane. Risco ou vulnerabilidade social? In: Textos \& Contextos (Porto Alegre), v. 11, n. 2, p. 301 - 308, ago./dez. 2012.

NUNES, Fernanda; CORSINO, Patrícia. A institucionalização da infância: antigas questões e novos desafios. In: CORSINO, Patrícia (org.). Educação Infantil: cotidiano e políticas. Campinas, SP: Autores Associados, 2012. (Coleção Educação Contemporânea), p. 13-30.

ROSEMBERG, Fulvia. Expansão da Educação Infantil e processo de exclusão. São Paulo: Cadernos de Pesquisa, n. 107, 1999, p. 7-14. 
SAMBRANO, Taciana Mirna. Relação instituição de educação infantil e família. In: ANGOTTI, Maristela (org.). Educação Infantil: Para que, para quem e por quê? $3^{\circ}$ ed. Alínea editora, 2010, p. 139-155.

SOARES, Natália. Direitos das crianças: utopia ou realidade? In: SARMENTO, Manuel; PINTO, Manuel. As crianças: contextos e identidades. Braga, Portugal, Coleção Infans: Centro de Estudos da Criança, 1997, p. 77-111.

SOUZA, Silvana Aparecida. Gestão democrática da escola e participação. In: Revista Educação e Políticas em Debate, v. 1, n. 1, - jan./jul. 2012, 173-187.

XIMENES, Salomão Barros. Direito à qualidade na educação básica: teoria e crítica. São Paulo: Quartier Latin, 2014.

$<$ http://www.curitiba.pr.gov.br/noticias/ fruet-sanciona-ldo-que-preve-investimento-de-30-em-educacaoem-2016/36976>.Acesso em 23/04/2017

$<$ http://www.curitiba.pr.gov.br/noticias/curitiba-vai-construir-mais-14-centros-municipais-de-educacaoinfantil/33408>. Acesso em: 23/04/2017

$<$ http:/ / www.gazetadopovo.com.br/educacao/ curitiba-vai-fechar-20-das-turmas-de-bercario-paraatender-criancas-de-4-a-5-anos-bu7qgzpvkkrsrdrmpni5alzh2> Acesso em:23/04/2017

<http://www.observatoriodopne.org.br/>Acesso em: 07/03/2016.

< http://www.ippuc.org.br/nossobairro/anexos>. Acesso em 25/06/2016. 